\title{
Study of Breast Lumps in Females up to 40 Years of Age at Government Medical College, Nagpur
}

\author{
Sumit Ashok Kumbhalwar ${ }^{1}$ Payal Jaywant Vaidya², Makrand Jaywant Vaidya³ \\ ${ }^{1}$ Department of General Surgery, CGHS, Nagpur, Maharashtra, India. \\ ${ }^{2}$ Department of Obstetrics and Gynaecology, WCL, Nagpur, Maharashtra, India. \\ ${ }^{3}$ Department of Orthopaedics, GMC, Nagpur, Maharashtra, India.
}

\section{ABSTRACT}

\section{BACKGROUND}

Breast diseases have been known to mankind since ancient times. However, earlier it was a matter of taboo and embarrassment that meant detection and diagnosis were rare. But the involvement of more women and actively bringing out the disease into open is a recent phenomenon. Various types of lesions from inflammation to carcinoma can affect the breast. Lump in breast is the commonest complaint which the patient presents to the surgeon. Different aetiologies of breast lump need different lines of management. We wanted to study the clinical profile of patients up to 40 years presenting with a discrete breast lump, diagnose different pathological conditions causing them and also study different investigations used for diagnosis.

\section{METHODS}

The study was done from October 2013 to December 2015 on a total of 305 consenting patients attending surgery outpatient department and those patients admitted in wards at government medical college, Nagpur were up to 40 years of age with a complaint of a breast lump. Clinical profiles of patients up to 40 years of age presenting with breast lumps were studied along with different investigations for diagnosis and different treatment modalities.

\section{RESULTS}

The highest incidence noted was fibroadenoma (178) in $58.36 \%$ of cases and the lowest incidence was of duct ectasia (3) in $0.98 \%$ of cases. The incidence of fibroadenoma in married women was $46.06 \%$ and in unmarried was $53.93 \%$. The lowest number of breast lump cases was found in the 10-20 yrs (59) age group and a maximum number of breast lump cases was found in the 21-30 yrs age group (140). Total 74 patients diagnosed with malignancy were the most commonly affected patients in the age group of $31-40$ yrs. Out of 305 patients with a history of self detected lump 87 i.e. $28.52 \%$ had mastalgia and 16 patients presented with nipple discharge. Ultrasound showed only their benign breast disease characteristic and the definitive diagnosis was not possible in them.

\section{CONCLUSIONS}

Rate of benign pathologies is comparatively much higher than malignant ones in young females; however, increasing trends of malignancy in this age group cannot be neglected. With the global trend towards an increase in the incidence of breast malignancy, for every patient with a breast lump, cytological / tissue diagnosis by an expert pathologist must be established, before a further line of treatment can be planned.

\section{KEY WORDS}

Fibroadenoma, Malignancy (CA Breast), OPD (Outpatient Department), Trucut Biopsy.
Corresponding Author: Dr. Sumit Ashok Kumbhalwar, Speciality Medical Officer, Department of General Surgery, CGHS, Nagpur, Maharashtra, India. E-mail: payalvaidya47@gmail.com

DOI: $10.14260 /$ jemds/2021/800

How to Cite This Article: Kumbhalwar SA, Vaidya PJ, Vaidya MJ. Study of breast lumps in females up to 40 years of age at government medical college, Nagpur. J Evolution Med Dent Sci 2021;10(45):3963-3967, $10.14260 /$ jemds/2021/800

Submission 09-11-2021,

Peer Review 17-11-2021,

Acceptance 22-12-2021,

Published 28-12-2021.

Copyright (C) 2021 Sumit Ashok Kumbhalwar et al. This is an open access article distributed under Creative Commons Attribution License [Attribution 4.0 International (CC BY 4.0)] 


\section{BACKGROUND}

Lump in the breast is the commonest complaint of patients with breast diseases. ${ }^{1}$ Overall benign pathologies are much more common than malignancy. Fibroadenoma of the breast is a common cause of benign breast lump in premenopausal women, ${ }^{2}$ accounting to breast biopsies performed today. Till now it was thought that breast lumps in females presenting at a younger age are mostly benign but current statistics suggest that pattern is changing. The incidence of breast cancer in women up to 40 years is low but more aggressive. There are certain benign breast conditions like chronic granulomatous mastitis and traumatic fat necrosis which closely mimic carcinoma and need differentiation. ${ }^{3}$

Early presentation and prompt diagnosis are essential to relieve the anxiety of non-neoplastic conditions and in case of carcinoma, it can save the patient from metastasis. Triple assessment is an accepted investigation that is carried out on outpatient department (OPD) basis.

\section{Objectives}

- To study the clinical profile of patients up to 40 years presenting with a discrete breast lump.

- To diagnose different pathological conditions causing discrete breast lumps.

- To study different investigations used for diagnosis.

\section{METHODS}

This cross-sectional, observational study was done with the permission of ethical committee IEC 203 from October 2013 to December 2015 on all consenting patients attending surgery outpatient department (OPD) and those admitted in wards at Government medical college, Nagpur up to 40 years of age with a complaint of the breast lump. On presentation, a detailed history was taken \& on examination, a definite lump was found and fine-needle aspiration cytology was done. If a fine needle aspiration cytology report confirmed the diagnosis further treatment was given. In addition, Trucut biopsy was done in every patient suspected to have malignancy, phyllodes tumour on clinical examination \& in the patients whom fine needle aspiration turned inconclusive.

\section{Inclusion Criteria}

All consenting female patients up to 40 years of age with discrete breast lumps.

\section{Exclusion Criteria}

1. Non consenting female patients.

2. Females above 40 years of age.

3. Patients with ill-defined/ nodular lump.

4. Patients clinically diagnosed with acute inflammatory conditions of the breast.

\section{Statistical Analysis}

It was done using the chi-square test. A P-value of $<0.05$ was considered statistically significant.

\section{RESULTS}

The highest incidence noted was fibroadenoma (178) i.e. $58.36 \%$ of cases and the lowest incidence of duct ectasia (3) in $0.98 \%$ cases. (Table 1 ).

The lowest number of cases was found in 10-20 years age group (59) \& a maximum number of cases in 21-30 years age group (140) followed by 31 - 40 year age group (Table 2). Fibroadenoma showed maximum incidence in 21-30 years. Malignancy occurred most frequently in the $31-40$ year age group (Table 2).

The mean age of patients and mean duration of presentation after the onset of $1^{\text {st }}$ symptom was 27 years of age and 3 months respectively. The age of cases for fibroadenoma ranged from 14 to 39 years and those for malignancy ranged from 23 to 40 years (Table 3 ).

Out of 305 patients with a history of self detected lump, 87 i.e. $28.52 \%$ had mastalgia and 16 patients presented with nipple discharge (Table 4).

$80.33 \%$ of patients with fibroadenoma did not have pain. 17 patients had cyclical and 18 patients had non-cyclical pain. 18 patients with menstrual irregularities were found $(10.42$ $\%)$. The incidence of fibroadenoma in married women was $46.06 \%$ and in unmarried women was $53.93 \%$. (Table 5)

The unilateral fibroadenoma was present in 164 patients whereas 09 had bilateral disease. The right breast was affected in 83 patients (46.62\%) and the left breast in 86 patients (48.31\%). Total no. of cases of multiple fibroadenomas were 36 (20.22 \%) (Table 6).

Most fibroadenomas were $2-3 \mathrm{~cm}$ in diameter that is approximately $70 \%$ and those more than $3 \mathrm{~cm}$ in size constituted approximately $15 \%$ of total fibroadenoma cases. Those patients with age $<20$ years and with lump size $<3 \mathrm{~cm}$ were counselled and priority was given for conservative management.

Out of 178 patients, 151 underwent excision, 27 patients were counselled and conservative management was considered in them. (Table 6)

Fibroadenoma most commonly involved the upper outer quadrant of the breast whereas the central quadrant and axilla were less involved. (Table 6)

Menstrual irregularities were present in $20.27 \%$ of patients with malignancies.

\begin{tabular}{|c|c|c|c|}
\hline Sr. No. & Disease & No. of Patients & Percentage \\
\hline 1 & Fibroadenoma & 178 & 58.36 \\
\hline 2 & Malignancy & 74 & 24.26 \\
\hline 3 & Antibioma & 16 & 05.24 \\
\hline 4 & Phyllodes tumor & 15 & 04.91 \\
\hline 5 & Galactocele & 09 & 02.95 \\
\hline 6 & $\begin{array}{c}\text { Chronic granulomatous } \\
\text { mastitis }\end{array}$ & 10 & 03.27 \\
\hline \multirow[t]{2}{*}{7} & Duct Ectasia & 03 & 0.98 \\
\hline & Total & 305 & 100 \\
\hline
\end{tabular}




\begin{tabular}{|c|c|c|c|c|}
\hline Sr. No. & Diseases & 10-20 Years & 21-30 Years & $31-40$ Years \\
\hline 1 & Fibroadenoma & 54 & 103 & 21 \\
\hline 2 & Malignancy & 0 & 10 & 64 \\
\hline 3 & Antibioma & 1 & 12 & 3 \\
\hline 4 & Phyllodes tumour & 4 & 5 & 6 \\
\hline 5 & Galactocele & 0 & 7 & 2 \\
\hline 6 & $\begin{array}{l}\text { Chronic granulomatous } \\
\text { mastitis }\end{array}$ & 0 & 7 & 3 \\
\hline \multirow[t]{2}{*}{7} & Duct papilloma & 0 & 1 & 2 \\
\hline & Total & 59 & 140 & 101 \\
\hline
\end{tabular}

\begin{tabular}{|c|c|c|c|c|c|}
\hline$\dot{\omega}$ & 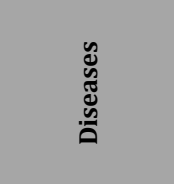 & 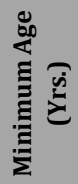 & 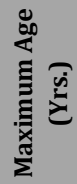 & 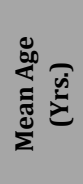 & 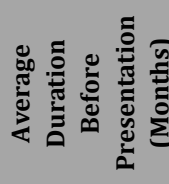 \\
\hline 1 & Fibroadenoma & 14 & 39 & 24 & 2 \\
\hline 2 & Malignancy & 23 & 40 & 34 & 5 \\
\hline 3 & Antibioma & 20 & 34 & 27 & 3 \\
\hline 4 & Phyllodes tumor & 16 & 40 & 29 & 5 \\
\hline 5 & Galactocele & 26 & 32 & 28 & 4 \\
\hline 6 & $\begin{array}{c}\text { Chronic } \\
\text { Granulomatous } \\
\text { mastitis }\end{array}$ & 22 & 40 & 30 & 3 \\
\hline 7 & Duct papilloma & 27 & 36 & 32 & 3 \\
\hline & Mean & 21 & 37 & 27 & 3 \\
\hline
\end{tabular}

\begin{tabular}{|ccc|}
\hline Complaints & No. of Patients & Percentage \\
Self detected lump & 305 & $100 \%$ \\
Pain & 87 & $28.52 \%$ \\
Nipple discharge & 16 & $5.33 \%$ \\
Table 4. Presenting Complaints of Women of $\mathbf{4 0}$ Years and Younger & \\
& with Breast Lump & \\
\hline
\end{tabular}

\begin{tabular}{|cccc|}
\hline Parameter & & Fibroadenoma & Percentage \\
& No pain & 143 & $80.33 \%$ \\
Pain & Cyclical pain & 17 & $09.55 \%$ \\
& Non-cyclical pain & 18 & $10.11 \%$ \\
Menstrual & Present & 18 & $10.42 \%$ \\
irregularities & Absent & 160 & $89.88 \%$ \\
& Nullipara & 95 & $53.37 \%$ \\
Obstetric History & Para 1 & 32 & $17.97 \%$ \\
& Para 2 & 24 & $13.48 \%$ \\
Marital status & Para 3 \& above & 27 & $15.16 \%$ \\
& Married & 82 & $46.06 \%$ \\
Family history & Unmarried & 96 & $53.93 \%$ \\
& Positive & 05 & $02.80 \%$ \\
\multicolumn{2}{c}{ Table 5. Symptomatology in Patients with Fibroadenoma } \\
\hline \multicolumn{2}{c}{} \\
\hline
\end{tabular}

\begin{tabular}{|c|c|c|c|}
\hline Parameter & & $\begin{array}{c}\text { Number of } \\
\text { Patients }\end{array}$ & Percentage \\
\hline \multirow{3}{*}{ Laterality } & Right & 83 & $46.62 \%$ \\
\hline & Left & 86 & $48.31 \%$ \\
\hline & Bilateral & 09 & $05.05 \%$ \\
\hline \multirow{3}{*}{ Number } & Single & 142 & $79.77 \%$ \\
\hline & 2 in one breast & 28 & $15.73 \%$ \\
\hline & $>$ in one breast & 08 & $04.49 \%$ \\
\hline \multirow{6}{*}{ Size } & $\begin{array}{c}\text { Maximum Diameter } \\
(\mathrm{cm})\end{array}$ & & \\
\hline & Up to $1 \mathrm{~cm}$ & 10 & $5.87 \%$ \\
\hline & $1-2 \mathrm{~cm}$ & 16 & $9.24 \%$ \\
\hline & $2-3 \mathrm{~cm}$ & 126 & $69.94 \%$ \\
\hline & $3-5 \mathrm{~cm}$ & 09 & $5.21 \%$ \\
\hline & 5 \& more & 17 & $9.82 \%$ \\
\hline \multirow{9}{*}{ Location } & $\begin{array}{l}\text { Upper outer } \\
\text { quadrant }\end{array}$ & & \\
\hline & Lower outer & 132 & $74.15 \%$ \\
\hline & quadrant & 10 & $12.82 \%$ \\
\hline & Lower inner & 17 & $09.55 \%$ \\
\hline & quadrant & 9 & $05.05 \%$ \\
\hline & Upper inner & 6 & $03.37 \%$ \\
\hline & quadrant & 4 & $02.24 \%$ \\
\hline & Central & & \\
\hline & Axillary tail & & \\
\hline
\end{tabular}

\begin{tabular}{|cccc|}
\hline $\begin{array}{c}\text { Parameters Related } \\
\text { to Ca Breast }\end{array}$ & $10-20$ & $\begin{array}{c}\text { Number of } \\
\text { Patients }\end{array}$ & Percentage \\
Age & $21-30$ & 0 & 0 \\
& $31-40$ & 21 & $28.37 \%$ \\
Menstrual irregularities & Present & 53 & $71.62 \%$ \\
& Absent & 15 & $20.27 \%$ \\
& Nullipara & 59 & $79.72 \%$ \\
Obstetric history & Para 1 & 18 & $10.81 \%$ \\
& Para 2 & 33 & $24.32 \%$ \\
& Para 3 \& above & 15 & $44.59 \%$ \\
& I & 3 & $20.27 \%$ \\
Stage wise cases & II A & 10 & $4.05 \%$ \\
& II B & 21 & $13.51 \%$ \\
& III A & 17 & $28.37 \%$ \\
& III B & 18 & $22.97 \%$ \\
& IV & 05 & $24.32 \%$ \\
& Operable CA & & $8.75 \%$ \\
& breast & 34 & $45.94 \%$ \\
Clinical staging & Large operable & 17 & $22.97 \%$ \\
& Locally & 18 & $24.32 \%$ \\
& advanced & 5 & $6.75 \%$ \\
\hline & Metastasis & \\
\hline Table 7. Discrete Breast Lump and Malignancy \\
\hline
\end{tabular}

\begin{tabular}{|c|c|c|c|}
\hline Pathology & $\begin{array}{c}\text { Number of Patients } \\
\text { Detected on USG } \\
\text { Consistent with Final } \\
\text { Diagnosis }\end{array}$ & $\begin{array}{c}\text { Total } \\
\text { Patients }\end{array}$ & $\begin{array}{c}\text { Diagnostic } \\
\text { Accuracy } \\
\text { (\%) }\end{array}$ \\
\hline Fibroadenoma & 158 & 178 & 88.76 \\
\hline Malignancy & 64 & 74 & 86.48 \\
\hline Antibioma & NCWFD & & \\
\hline Phyllodes tumour & NCWFD & & \\
\hline Galactocele & 09 & 9 & 100 \\
\hline $\begin{array}{l}\text { Chronic Granulomatous } \\
\text { mastitis }\end{array}$ & NCWFD & & \\
\hline Duct ectasia & 1 & 3 & 33.33 \\
\hline \multicolumn{4}{|c|}{$\begin{array}{c}\text { Table 8. Diagnostic Accuracy of Ultrasound in the Detection } \\
\text { of Breast Lumps }\end{array}$} \\
\hline
\end{tabular}

\section{DISCUSSION}

A total of 305 consenting patients presenting with discrete breast lumps were studied.

The different conditions causing a lump in the breast in this age group in order of frequency were as follows:

1. Commonest was fibroadenoma 178 cases (58.36\%)

2. $2^{\text {nd }}$ was malignancy 74 cases $(24.26 \%)$

3. $3^{\text {rd }}$ was antibioma 16 cases

4. Phyllodes tumor 15 cases.

5. Other conditions causing the same were chronic granulomatous mastitis (10), galactocoele (9), duct ectasia (3).

Tibor de Cholnoky (1943) ${ }^{4}$ stated that cancer of the breast in patients under 30 years of age constituted $2 \%$ of all the breast cancers. In the present study, incidence of cancer of the breast in patients under 30 years was 10 out of 74 i.e. $13.51 \%$.

Stone AM, Shankar RI \& McCarthy K (1977) ${ }^{5}$ studied cases of breast lumps in adolescence \& found fibroadenoma to be commonest i.e. $70 \%$. In our study, total no of cases of fibroadenoma was found to be 178 out of 305 i.e. $58.36 \%$.

Glacomelli $(1935)^{6}$ reported the mean age for fibroadenoma as 21 years whereas Haagensen $\mathrm{CD}^{7}$ (1971) reported it as 25 years. Gheschikter ${ }^{8}$ (1945) found the highest no. of patients with fibroadenoma in the age group of 21-25 years, whereas Oliver Major ${ }^{9}$ (1945) reported the highest no. in the age group of 20-24 years. Goldberg VE10 
(1968) stated that fibroadenoma is the commonest condition causing breast lump between 15-35 years. Abhishek Vijaykumar et al.11 (2012) found the incidence of fibroadenoma as the commonest in the age group of 16-20 years i.e. $66.1 \%$ with the mean age being 27 years and 43.8 $\%$ incidence in the upper outer quadrant. In the present series, the age group having a maximum number of patients was 21-30 years and the mean age for fibroadenoma presentation was 24 years and also it occurred most frequently in the outer upper quadrant 127 (73.41\%).

D. N. Ader et al. (1999) ${ }^{12}$ found the incidence of mastalgia to be $16 \%$. In our study, 87 patients (29\%) were found to have mastalgia.

William Donegan ${ }^{13}$ stated incidence of $17.5 \%$ cases of multiple fibroadenomas of which $88 \%$ were bilateral \& $8.2 \%$ were unilateral. In the present study, the incidence of multiple fibroadenomas was $20.78 \%$ of which 9 were bilateral.

Abhishek Vljaykumar et al. (2012) ${ }^{11}$ found a ratio of incidence of fibroadenoma in unmarried to married patients as $38.1 \%$ to $61.9 \%$. In our study, this ratio was $53.93 \%$ to $47.07 \%$.

Wilson Onuigbo (2000) ${ }^{14}$ found the percentage of fibroadenoma in right breast as $15 \%$, in left breast as $48.7 \%$ \& both 10.9 cases and $3 \mathrm{~cm}$ size fibroadenoma is most common. In our study, out of 178 fibroadenomas, 83 cases were on the right side, 86 on the left side \& 9 bilateral and commonest size 2-3 cm i.e. 126 (70.78\%).

Carey K Anders et al. (2009) ${ }^{15}$ mentions incidence of breast cancer in females up to 40 years as $7 \%$. Marcus et al. ${ }^{16}$ found an increased incidence of ductal cancer \& medullary cancer. Sariego et al. ${ }^{17}$ (1995) found that $93 \%$ of patients had infiltrate ductal carcinoma below 35 years. In our study, 75 had malignancy of which 72 were having infiltrating duct carcinoma, 1 was having lobular carcinoma, 1 with comedocarcinoma. Razif SM, Sulaiman S (2011) ${ }^{18}$ shared their view with Anderson \& Badzioch (1985) ${ }^{19}$ mentioning a strong relationship between family history \& early-onset breast cancer. In our study, 5 cases had a family history, and the rest patients were not having a family history which could possibly be due to the increasing prevalence of sporadic breast cancer. Kenfield, Haagensen \& Cooley ${ }^{20}$ found the average size of tumour size as $3.9 \mathrm{~cm}$ and lymph nodes were palpable in 8 patients. In our study, 51 patients had clinically positive lymph nodes.

Ashish K Shukla et al. (2015) ${ }^{21}$ found that the overall sensitivity of ultrasound was $81.67 \%$, fibroadenoma had the highest diagnostic accuracy of $85.71 \%$ followed by carcinoma (81.25\%). Sareen $M$ et al. $(2014)^{22}$ found the overall sensitivity for ultrasound as $84 \%$, accuracy in detection of carcinoma was $84.61 \%$. In our study, diagnostic accuracy was $93.825 \%$, for carcinoma it was $86.48 \%$ \& that for galactocoele it was $100 \%$ whereas for duct ectasia it was $33.33 \%$.

\section{Summary}

305 cases of discrete breast lumps occurring in women up to 40 years were studied during the study period. The commonest cause of lump was fibroadenoma comprising $58.36 \%$ followed by malignancy (24.26\%), antibioma (5.24
$\%)$, phyllodes tumour (4.91 \%), chronic granulomatous mastitis (3.27 \%) and duct ectasia (0.98\%).

Fibroadenoma was most common in the age group 21-30 years $(57.86 \%)$ with a mean age of 24 years. The commonest size of fibroadenoma found was $2-3 \mathrm{~cm}(67.97 \%)$ and the upper outer was the commonest quadrant $(74.15 \%)$. Out of 178 cases, 17 were of size more than $5 \mathrm{~cm}, 16$ cases with size 1-2 cm, 10 cases of size up to $1 \mathrm{~cm}$, rest 9 were of size $3-5 \mathrm{~cm}$. $10.40 \%$ of cases had menstrual irregularities. 83 fibroadenoma cases were involving the right side $(46.20 \%)$, 86 cases (48.31\%) on the left side and 9 (5.05\%) were bilateral.

Malignancy was most common in the age group 31-40 years with the mean age being 34 years, comprising $71.62 \%$ of total patients. $97.29 \%$ of patients were of ductal carcinoma, 1 infiltrating lobular carcinoma, another was comedocarcinoma. 8 cases (10.81) were nulliparous with 3 presenting with advanced breast carcinoma. 5 cases $(2.89 \%)$ had a family history of breast cancer. The average duration of the lump for presentation to a clinician in case of malignancy was 5 months. The increasing duration of the lump was associated with advanced lesions. There were 34 cases of early invasive breast cancer i.e., stage I, IIA, IIB, contributing $45.94 \%$ of patients. The highest number was found in stage IIB $21(28.37 \%$ ) followed by stage IIIB 18 ( $24.32 \%)$, stage IIIA 17, stage IIA 10, stage IV 5 and stage I 3 cases. 5 patients had distant metastasis and were given palliative therapy. Thus $6.75 \%$ were inoperable. 51(68.91 \%) cases had clinically positive lymph nodes.

Ultrasound showed a diagnostic accuracy of $88.76 \%$, $86.48 \%, 100 \%$ \& $33 \%$ for fibroadenoma, malignancy, galactocoele and duct ectasia respectively.

\section{CONCLUSIONS}

Breast lump occurring in women up to 40 years of age is a common presentation. The evaluation in these patients becomes difficult due to continuous dynamic changes occurring in the breast. This difficulty further increase, as the incidence of benign pathologies, is overwhelmingly high and that of malignancy is low. Further malignancy occurring in this age group is supposed to be highly aggressive. Thus, study shows that rates of benign pathologies are comparatively much higher than malignancy in young females. However, increasing trends of malignancy in this age group cannot be neglected. So high index of suspicion should be kept for malignancy, even when the incidence of same in this age is low as compared to the older age group ( $>40$ years). With the global trend towards an increase in the incidence of breast malignancy, for every patient with a breast lump, cytological / tissue diagnosis by an expert pathologist must be established, before a further line of treatment can be planned.

Data sharing statement provided by the authors is available with the full text of this article at jemds.com.

Financial or other competing interests: None.

Disclosure forms provided by the authors are available with the full text of this article at jemds.com. 


\section{REFERENCES}

[1] Das S. A manual on clinical surgery. $9^{\text {th }}$ edn, Kolkata: S Das 2011:406-22.

[2] Houssami N, Cheung MN, Dixon JM. Fibroadenoma of the breast. Med J Aust 2001;174(4):185-8.

[3] Guray M, Sahin AA. Benign breast diseases: classification, diagnosis and management. Oncologist 2006;11(5):43549.

[4] De Cholnoky T. Mammary cancer in youth. Surg Gynaecol Obstet 1943;77:55-60.

[5] Stone AM, Shankar RI, McCarthy K. Adolescent breast masses. Am J Surg 1977;135:275-7.

[6] Glacomelli A. Disease of breast. 2nd edn. Philadelphia: W.B. Saunders 1935: p. 1969.

[7] Haagensen CD. Disease of breast. $2^{\text {nd }}$ edn. Philadelphia: W.B. Saunders 1971: p. 214.

[8] Geschikter CF. Disease of breast. 2nd edn. Philadelphia: J.B. Lippincott 1945.

[9] Oliver CP. Radiation genetics. Quart Rev Biol 1934;9(4):381.

[10] Goldenberg VE, Wiegenstein L, Mottet NK. Florid breast fibroadenoma's in patients taking hormonal oral contraceptives. American Journal of Clinical Pathology 1968;49(1):52-9.

[11] Vijaykumar A, Ajitha MB, Shivaswamy BS, et al. A Systemic study on fibroadenoma of the breast. Eur J Surg Sci 2012;3(3):80-5.

[12] Ader DN, Shriver CD, Browne MW. Cyclical mastalgia: premenstrual syndrome or recurrent pain disorder? J Psychosom Obstet Gynaecol 1999;20(4):198-202.
[13] Donegan WL, Sprrat JS. Cancer of the breast. $4^{\text {th }}$ edn. WB Saunders 1995.

[14] Onuigbo W. Breast fibroadenoma in teenage females. Turkish Journal of Paediatrics 2003;45(4):326-8.

[15] Anders CK, Johnson R, Litton J, et al. Breast cancer before age of 40 years. Semin Oncol 2009;36(3):237-49.

[16] Agnarsson BA, Jonasson JG, Bjornsdottir IB, et al. Inherited BRCA2 mutation associated with high grade breast cancer. Breast Cancer Res Treat 1998;47(2):1217.

[17] Sariego J, Zrada S, Byrd M, et al. Breast cancer in young women. Am J Surg 1995;170:243-5.

[18] Razif SM, Sulaiman S, Hanie SS, et al. The contribution of reproductive factors and family history towards premenopausal breast cancer risk in Kuala Lumpur, Malaysia. Med J Malaysia 2011;66(3):220-6.

[19] Anderson DE, Badzioch MD. Risk of familial breast cancer. Cancer 1985;56(2):383-7.

[20] Kleinfeld G, Haagensen CD, Cooley E. Age and menstrual status as prognostic factors in carcinoma of the breast. Ann Surg 1963;157(4):600-5.

[21] Shukla AK, Chauhan BKS, Verma V. Study of Role of Ultrasonography in Detection of Palpable Breast Lump in a Tertiary Care Teaching Hospital. Int J Med Res 2015;1(3):88-91.

[22] Sareen M, Tiwari P, Tiwari M. Evaluation of breast lumps by ultrasonography: a study in rural teaching institution. Journal of Evolution of Medical and Dental Sciences 2014;3(7):7406-10. 